\title{
Study on Construction Technology of Tunnel Entrance on High Steep Slope of Sichuan-Tibet Railway
}

\author{
Yishuo Liu"12, Qiangxun Wang, Jiantao Guo ${ }^{12}$, Wenyuan $\mathrm{Gao}^{12}$ and Jingge $\mathrm{Li}^{12}$ \\ ${ }^{1}$ China State Construction Technical Center, Beijing, 101300, China \\ ${ }^{2}$ China State Construction Engineering Industry Technology Research Institute Co., Ltd, Beijing, 101300, \\ China
}

\begin{abstract}
The geological environment along the Sichuan-Tibet railway has the characteristics of plate splitting, frequent geological disasters, complex topography, large topography, cold climate, high cold and anoxia, etc. It is recognized by the world as one of the most difficult projects so far. Based on the construction of the tunnel entrance on the high and steep slope of the Sichuan-Tibet Railway, this paper conducts research on the construction of the tunnel construction, the reinforcement of the tunnel entrance and the protection of high and steep slopes. The integrated" tunnel entrance reinforcement system and the "carbon fiber lightweight active protection net" technology for slope protection are expected to provide a reference for the construction of the tunnel entrance of the Sichuan-Tibet railway high and steep slope.
\end{abstract}

\section{Introduction}

The Sichuan-Tibet Railway passes through five geomorphic units, namely the Sichuan Basin, the mountain and valley area of western Sichuan, the plateau area of western Sichuan, the Hengduan mountainous area in south-eastern Tibet, and the valley bottom area of southern Tibet. The route passes through the region with high mountains and deep valleys and extremely complex topographical conditions. The area passed by the line has the characteristics of high cold, lack of oxygen, large temperature difference, strong ultraviolet rays, and dry climate. The Sichuan-Tibet Railway has crossed seven major rivers including the Dadu River, the Yalong River, the Jinsha River, the Lancang River, the Nu River, the Palong Zangbo and the Yarlung Zangbo River. Pass through eight high mountains including Erlang Mountain, Zheduo Mountain, Gaoersi Mountain, Shaluli Mountain, Mangkang Mountain, Ta Nian Taweng Mountain, Boshula Mountain, and Sejila Mountain. This is the socalled "eight ups and seven downs" [1-4]. The topographic map along the Sichuan-Tibet Railway is shown in Figure 1. The area covered by the SichuanTibet Railway is ups and downs. It is located in the central and eastern Qinghai-Tibet Plateau formed by the collision and uplift of the Eurasian plate and the Indian plate. The mountains along the line are high and deep, with mixed strata and lithology, neotectonic movement is intense, and deep and large active faults are extensive. Distribution, strong internal and external dynamic geological effects, frequent strong earthquakes, large magnitudes, high intensity, collapses, landslides, mudslides and other (induced) large (major) bad geological bodies (groups) and development of special rock and soil, their types and scales All are rare; the slopes of the river valley are poor in stability, the climate is harsh and changeable, and the difficulty of construction is unprecedented.

The mountains along the Sichuan-Tibet Railway are high and deep, and the significant terrain height difference is bound to affect the construction. The main impacts are: 1. The layout of temporary construction projects is difficult, and the transportation of materials and equipment is difficult. 2. The entrance of the tunnel is located on a steep slope and construction is difficult. 3 . The construction of the slope protection of the tunnel entrance is difficult. Based on the construction of the tunnel opening on the steep slope of the Sichuan-Tibet Railway, the article carried out research on the construction of the tunnel construction access road, the reinforcement of the entrance and the protection of steep slopes. 


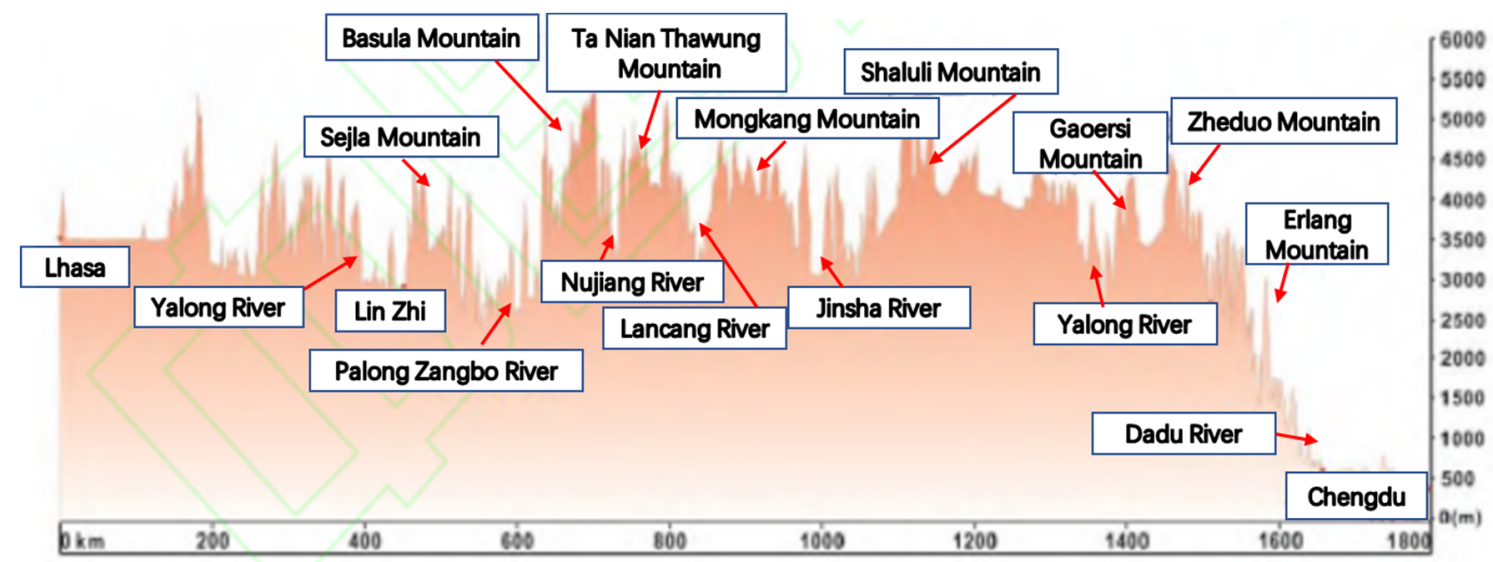

Figure 1. The topographic map along the Sichuan-Tibet Railway

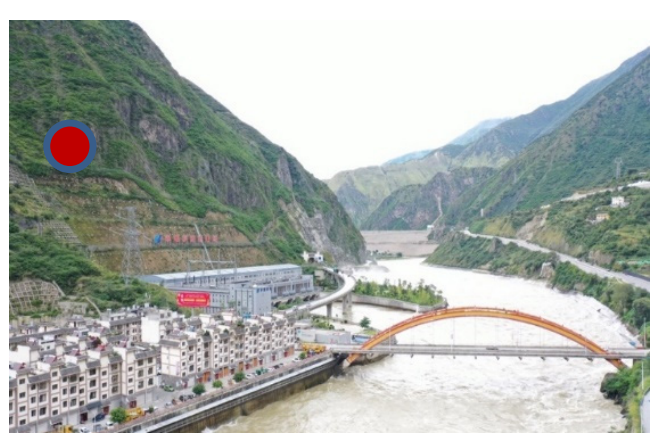

Figure 2. Entrance of Baolingshan Tunnel

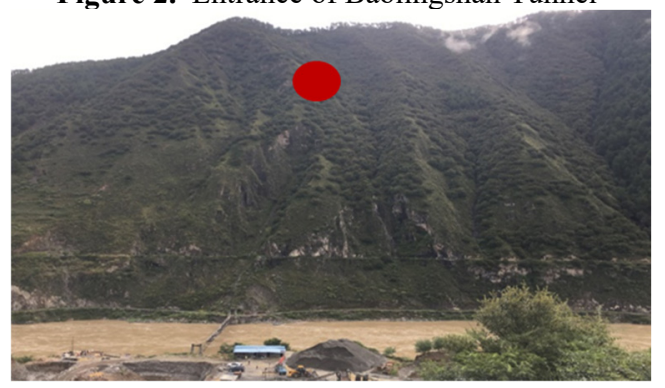

Figure 3. Wangjia Tunnel Exit

\section{Reinforcement technology of tunnel opening in steep terrain}

The entrance of the tunnel is the throat of the tunnel and also one of the weak links of the entire tunnel. Generally speaking, the rock and soil at the entrance are severely weathered, and the topography and geological conditions are relatively poor. Due to unfavorable factors such as biased terrain, surface joints and fissures, groundwater, rainfall, etc., the tunnel opening area is likely to be unstable during construction, as shown in Figure 4. The instability of the tunnel entrance area is mainly manifested as surface cracking, sliding, sinking, collapse of the tunnel face, protrusion and other diseases. Once the disease occurs, these diseases must be cured. The construction period is long, the investment is large, and the social impact is large. Therefore, the stability of the tunnel entrance is directly related to the difficulty of tunnel construction and operational safety. How to take effective measures under complex geological conditions to avoid the instability of the tunnel entrance is a key concern in design and construction.
In the construction of mountain tunnels, pipe shed arches are often set for broken and soft opening sections, and long pipe sheds are erected to reinforce the opening section. However, for sections with very poor geological conditions and severe shallow buried bias pressure, even if a long pipe shed is built, during the undercut construction, the tunnel entrance may be overloaded on the upside slope, causing the pipe shed arch to follow the axial direction of the tunnel. Slip: The large slope of the cross slope at the entrance of the tunnel, the excessive load on the slope, and the serious bias pressure cause the pipe-sheathed arch to slip along the slope. The bearing capacity of the pipe-sheathed arch foundation is poor, which leads to the overall sinking of the pipe-sheathed arch [5-10]. This led to accidents such as the collapse of the tunnel roof and the cracking of the main structure.

For the high and steep slope tunnel encountered along the Sichuan-Tibet Railway, how to safely enter the tunnel and ensure the stability of the upward slope is the key to construction. In the case of a small area of brushing the slope, this paper studies the construction of the tunnel under the conditions of poor self-stability, easy landslides, collapses, and difficult protection of the broken high and steep slopes, and proposes a new type of "pile-wall-arch integration" The arch structure of the composite pipe shed is shown in Figure 5. This structure improves the vertical bearing capacity and longitudinal anti-slip capacity of the pipe-sheath arch structure, and at the same time improves the anti-slide resistance of the anti-slide piles on both sides, enhances the protection of upside slopes, and achieves less excavation or "zero excavation" of the mountain And the purpose of safe entry.

The construction method of the new "pile, wall and arch integration" composite pipe shed arch structure includes the following steps:

Arrange two anti-slide piles on both sides of the opening surface of the tunnel entrance, and determine the size of anti-slide piles according to the load of the side slope. 


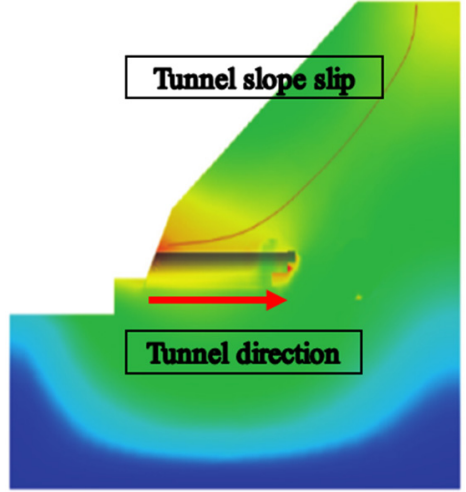

Figure4. Simulation diagram of upside slope sliding caused by tunnel construction

During the construction of anti-slide piles, pre-embed steel sleeves and angle steel in the anti-slide piles.
Using the reserved core soil method to excavate the rock and soil at the location of the tunnel entrance pipe shed.

Construct the steel arch in the arch of the pipe shed, and the steel arch is welded with the pre-embedded angle steel in the anti-slide pile to form a whole. Since the antislide piles extend into the rock and soil at the bottom of the tunnel deeper, they can provide a stable foundation for the pipe shed arch.

The arch of the pipe shed is connected with the prereinforced pile through the connecting steel bars inserted into the pre-embedded steel sleeve to form an integral structure.

Pour concrete as a whole to form an integral structure of anti-slide pile + wall + pipe shed arch.

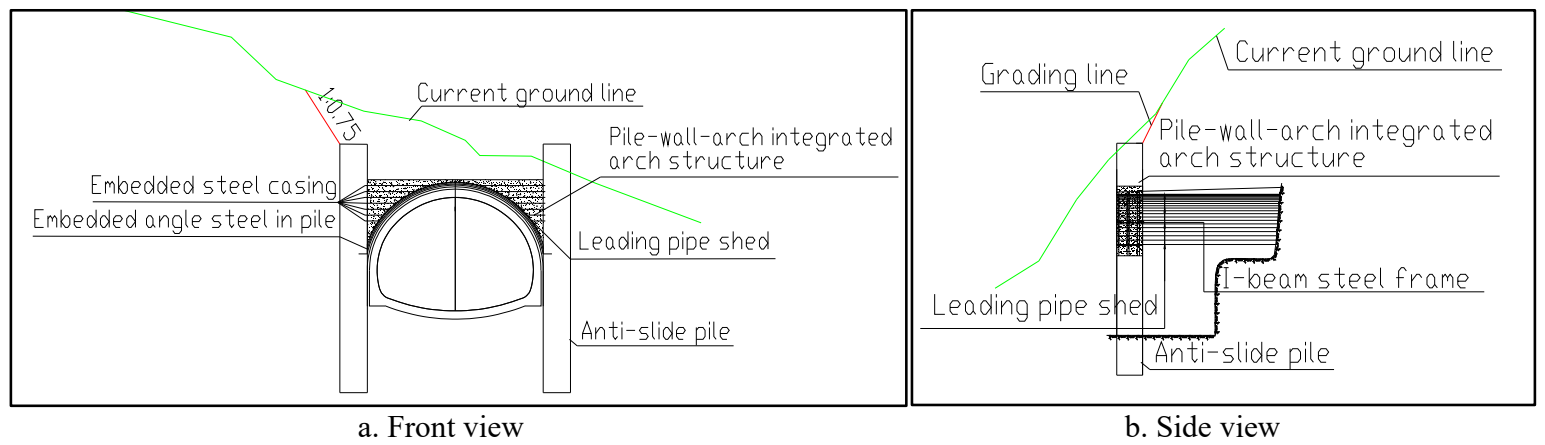

Figure5. The structure diagram of the composite pipe shed arch

This structure integrates the pipe shed arch structure with the anti-slide piles on both sides. The new structure can effectively prevent the tunnel opening from collapsing and slope slippage by setting up this new structure in the steep terrain, biased pressure, and broken and soft opening section. In the case of a small amount of excavation, the safe entry of the tunnel is guaranteed.

\section{Conclusion}

Based on the high and steep slope at the entrance of the Sichuan-Tibet railway tunnel, this paper conducts research on the construction of access roads, reinforcement of the entrance, and protection of the slope of the mountain tunnel with high and steep slopes. The following conclusions are drawn:

Aiming at the severe environment such as poor selfstability, easy landslide, and easy collapse of the Sichuan-Tibet railway tunnel, a new type of "integrated pile, wall and arch" composite The arch structure of the pipe shed can effectively prevent the tunnel entrance from collapsing and slope slippage, and ensure the safe entry of the tunnel under the condition of little excavation.

\section{References}

1. CHEN Yang. Study on the Deformation Characteristics of Soft Broken Surrounding Rock and Optimization of Excavation and Support in
Tunnel Portal Section [D]. Qingdao: Qingdao University of Technology, 2018.

2. YAN Liyuan. Analysis on Stability of Slope at Tunnel Portal and Study on Rationality of Relevant Support Measures [D]. Changsha. Central South University, 2010.

3. XU Yong, CHEN Xi. On Slope Support at Tunnel Portal in Earthquake Region[J]. Henan Building Material, 2009(4):53-54.

4. WANG Ting. Key Construction Techniques for the Portal of Large-span Tunnel under Unfavorable Geological Conditions [D]. Beijing: Beijing Jiaotong University,2008.

5. ZHANG Haoliang. Research on the Slope Stability of Tunnel Entrance in Loess [D]. Lanzhou: Lanzhou University of Technology,2013.

6. HAO Shefeng, JIANG Bo, YU Yongxiang, et al. Stability Analysis and Treatment Evaluation on High-Steep Rocky Slope in SouthExit of Qinwangshan Tunnel[J]. The Chinese Journal of Geological Hazard and Control, 2019, 30(2): 89-97.

7. ZHU Yanpeng, ZHANG Haoliang, LI Zhong, et al. Influence of Large-Section Tunnel Construction on Slope Stability[J]. Journal of Lanzhou University of Technology, 2014, 40(3): 120-125.

8. WANG Hui. Construction Technology of Safety Protection of High Slope Tunnel Entrance[J]. Northern Communications, 2018(8):75-77. 
9. JIAO Mandai, LIU Tao, CHAI Hengshan. Stability Analysis of High and Steep Open-pit Slopes Based on Strength Reduction Method [J].Mining Research and Development, 2018, 38(11):66-70.

10. ZHU Yibing. Research on Stability of the High and Steep Slope and Control Technique at the Doublearch Tunnel Entrance[D]. Chongqing: Chongqing Jiaotong University,2017. 